Milos Poliak - Jana Tomicova - Marek Jaskiewicz - Pawel Drozdziel - Natalia Lakhmetkina

\title{
IDENTIFICATION OF NEUTRALIZATION OF THE CMR DOCUMENTS IN EUROPEAN UNION CONDITIONS
}

Year 1956 was an important year for international road and freight transport. By this year Convention on the Contract for the International Carriage of Goods by Road (CMR) was made. The basic purpose of the Convention was to unify the rules in the international carriage of goods and thereby promote development of international trade. From the practical point of view, this was very important for both carriers and transporters. This Convention also describes the most important document in the international carriage of goods, which includes the consignment note of CMR as well. Recently this document is often associated with the term neutralization. Objective of this article was to clarify the meaning of this phrase in transport. In addition, the aim was to find out in what range carriers have real experience with neutralization of the consignment note of the CMR during the transport, for what types of goods and on what types of routes is the neutralization being used the most.

Keywords: document, CMR, convention, agreement, transportation

\section{Introduction}

Transport is an important need for humanity and is also a necessary requirement for the functionality of international trade. Within the EU, the road transport has gradually gained a dominant position, mainly due to reasons such as quality and variety of road network within the EU, flexibility, speed, convenience, adaptability and many others [1-2]. Within international trade it is possible to transport goods only based on the conclusion of the transport contract. Concluding a transport contract for international transport is much easier thanks to the CMR [3]. Fortunately for carriers, in 1956 the CMR was concluded in Geneva. The purpose is to set the standards of conditions, which are being used in an agreement about transport of goods within the cross-border transportation of goods. An important role during the international transportation of goods is being held by a consignment note of the CMR [4-5]. It is a document about conclusion of an agreement on transport and at the same time it is a document about acceptance of a package by a carrier.

Recently, in the transportation segment, a new term is being used very often. This new term is called "neutralization of consignment note of the CMR". There is no any legal prescription or standard, which would define this term. The aim of this article is to explain what the term "neutralization of consignment note of the CMR" means. The intention is also to verify if the neutralization of consignment note of the CMR is being really used in international road transport and if it is being used only for transport of certain goods, like for example food. Next, it is also needed to know if transport documents are being traded during the transportation from or into Slovakia, so by that one would know if it is being used only for international transports. For verification of these hypotheses a survey among carriers was conducted.

\section{Analysis of the current state}

Concluding a contract of carriage during the international transport would be significantly more complicated for the carrier with the absence of the CMR. In the absence thereof, the carrier would have to know all the national transport regulations of the countries through, which he would transport the goods. Due to the differences in legislation and their inconsistent interpretation, many misunderstandings could be made for example during the contracts conclusion and demands for a carrier. This was the main reason for concluding a CMR in 1956 in Geneva [6]. In addition, this is an agreement on transport in an international road and freight transport. Its main purpose is to merge rules inside an international road group of transporters and at the same time support expansion of an international market. In real practice, this has a huge impact for carriers and transporters. If this convention would not exist everything would be managed by national regulations of a current country [7]. In 1978 protocol for convention was signed in Geneva. It included only regulation of an article 23 that consists of information about replacement of damage. Later in 2008 this convention was completed by an extra protocol, while this addition was focused on possibility of using electronic freight note [8]. International

\footnotetext{
Milos Poliak ${ }^{1, *}$, Jana Tomicova ${ }^{1}$, Marek Jaskiewicz $^{2}$, Pawel Drozdziel ${ }^{3}$, Natalia Lakhmetkina ${ }^{4}$

${ }^{1}$ Department of Road and Urban Transport, University of Zilina, Slovakia

${ }^{2}$ Department of Motor Vehicles and Transport, Kielce University of Technology, Poland

${ }^{3}$ Politechnika Lubelska, Lublin, Poland

${ }^{4}$ Logistics Transport Systems and Technologies, Russian University of Transport (RUT - MIIT), Moscow, Russia

*E-mail of corresponding author: milos.poliak@fpedas.uniza.sk
} 


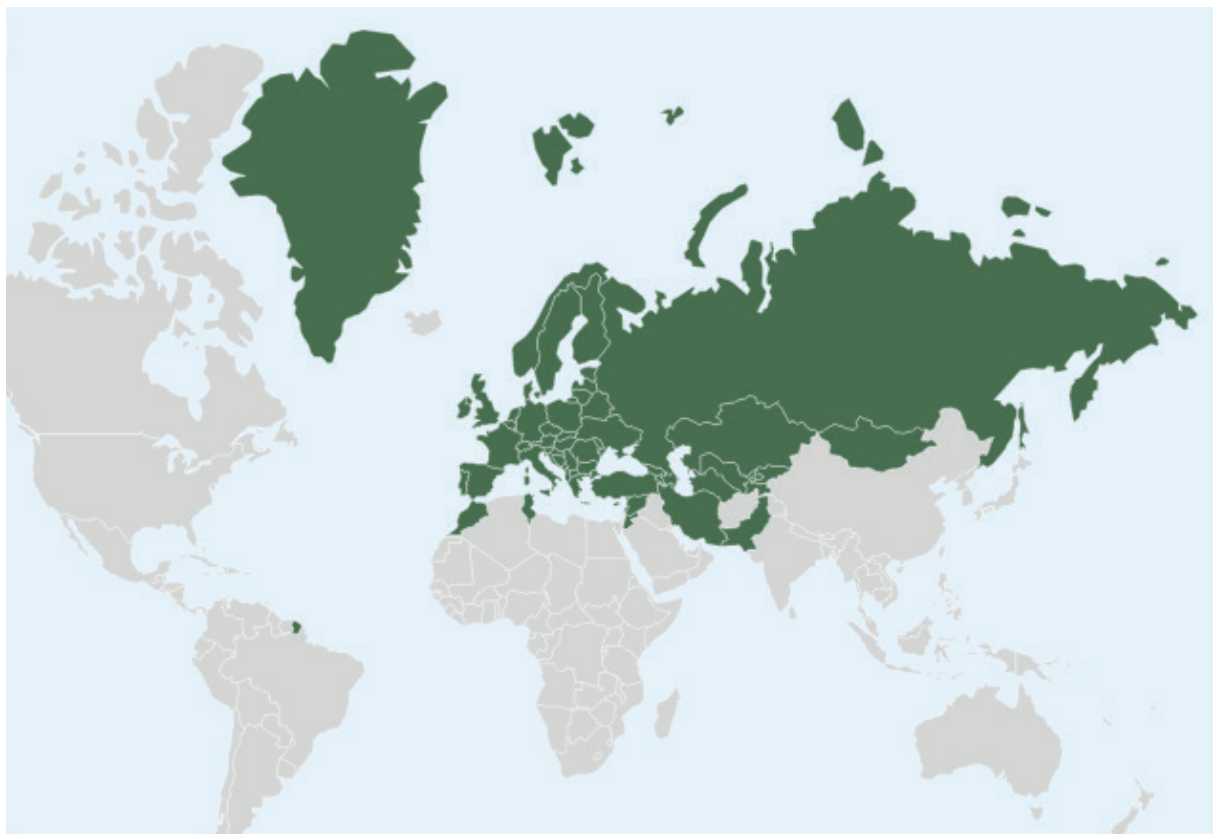

Figure 1 Contracting parties of the CMR, [11]

transport is transport where loading of goods is happening in one state and unloading of goods is done in another state or country. In order to be able to apply the CMR during the international transport of goods, either a place of loading or a place of unloading must be in a country that has signed the CMR [9]. There are three exceptions when it is not possible to make a transport under the CMR, even though it is an international carriage. It does not apply to the carriage of postal items, dead bodies and migratory uppers. The main reason why these consignments cannot be transported under the terms of the CMR is the fact that the value of these packages cannot be determined objectively. Because of that, it is not possible to set the level of responsibility of a carrier during the transport. The Convention has been gradually ratified by individual European countries, but the non-European countries are the contracting parties as well. Currently there is 56 countries who signed the CMR while 45 of them ratified the protocol as well [10]. Figure 1 shows the member countries of the CMR Convention.

The CMR sets the rules, rights, obligations and responsibilities of the carrier and the transporter. It also regulates the conclusion and realization of transport contracts, as well as the procedures for claiming damages. It specifies what the accompanying documents for transport should contain. It describes the most important document in the international transport of goods - consignment note of the CMR [12]. It is an official document that has a standardized form and is usually written in two languages. It is prepared in three original copies, signed by the sender and the carrier. If permitted by the law of the current country where the consignment note is drawn up, these signatures may be printed or replaced by the stamps of the sender and the carrier. The first (red) letter is addressed to the sender and constitutes proof that the goods have been handed over to the carrier by the sender for transport. The second (blue) letter is intended for the receiver of the goods to know how many goods to take over from the carrier. The third (green) letter is addressed to the transporter and confirms that the goods have been handed over to the receiver. The transport note is a trustable note about conclusion of transport contract, as well as a note about accepting the package if opposite is not claimed [13]. If the transport note does not contain reservations from the carrier, the legal presumption is that the package and its cover was in a perfect state during the process of accepting it and that number of pieces and its marks were matching data from the transport note [14-15].

The carrier's liability shall commence at the moment of acceptance of the goods for transport and ends at the moment of delivery of the goods to the receiver. The carrier is responsible for damage or loss of the package during the transport. He is also responsible for exceeding the delivery time. The Carrier shall, under the provisions of the CMR, be reliable for damages for the total or partial loss of the package incurred during the transport. Compensation for damages is calculated from the value of package at the place and time of its acceptance for transport [16]. Value of package is determined by the stock exchange price; if there is no stock exchange price, then according to the current market price. If there is neither stock exchange nor market price, then according to the general value of goods of the same kind and quality. The CMR provides that damages may not exceed a fixed amount per kilogram of missing gross weight of package. In the original version of the CMR, damages may not exceed 25 francs per kilogram of missing gross weight. Franc means a golden franc weighing $10 / 31$ grams and a purity of 0.900 . This limitation of responsibility applies only in eleven countries that have not yet ratified the CMR Protocol. The remaining countries have significantly reduced the responsibility of carriers by ratifying the Protocol. This is because the gold franc is replaced by a Special Drawing Rights Unit (SDR). The 


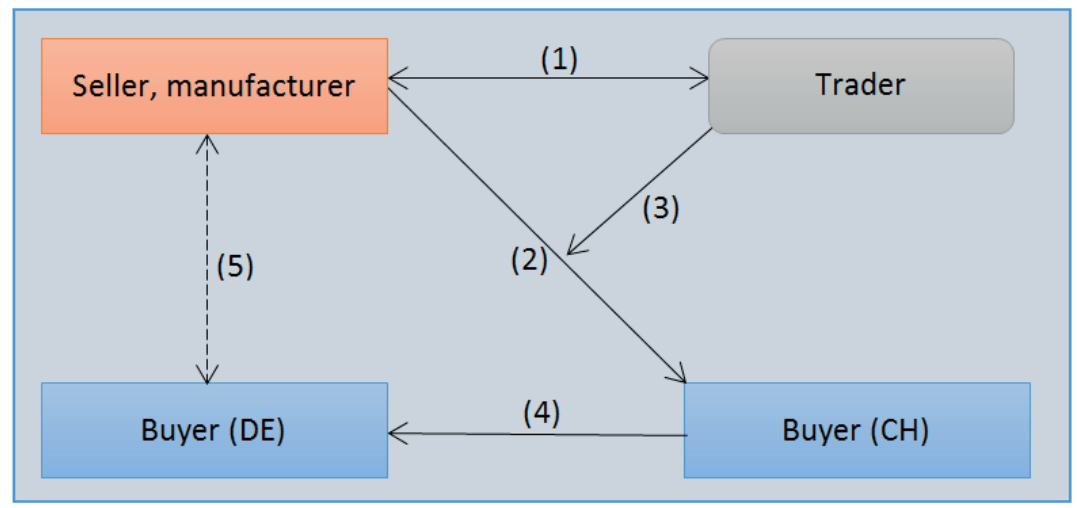

Figure 2 Scheme of neutralization of transport document in parallel trade

Carrier is obliged under the Protocol to pay the owner of the transported goods in the amount of 8.33 SDR per each kilogram of damaged, destroyed or lost goods. The specific value of the SDR depends on the exchange rate of the SDR and the EUR. In addition, the carrier must pay the transport, customs and other expenses associated with the transport of a package. This responsibility value is also covered by the liability insurance of the carrier. However, if the consignment note of CMR states the value of the package or a particular interest in delivery, the carrier is reliable for the full value of the damaged goods. In such a case, in the event of total loss of package, the carrier must pay the full value of the goods, as well as import, customs, VAT, excise duties, etc. If this value is higher than the amount of the insurance coverage of the carrier's liability resulting from the CMR, it is recommended that these goods are insured by the carrier. This applies in particular to light and expensive goods. If the delivery time is exceeded and receiver proves that because of this he received damage, the carrier is obliged to pay the damages only up to the amount of the transport charge [17-18]. This analysis confirms that the CMR is an important legal standard for international road freight transport. It is important for carrier and transporter, as well. The consignment note of the CMR constitutes a credible document for both parties. Consignment note of CMR is also a credible document for third parties, e.g. customs offices, insurance companies, etc. It is therefore necessary to consider further whether the consignment note of the CMR can be neutralized under the rules currently in force and whether the neutralization of the consignment note of the CMR does not jeopardize the functioning of the existing system.

\section{Neutralization of the CMR consignment note and its reasons}

Document neutralization is a procedure known only for the transport sector. Unfortunately, the authors of this paper have not been able to determine the definition of this phrase in any legislation or standards. Nevertheless, this connection has been known and used in road freight transport for several years. The word neutralization has several meanings. In general, it means cancellation of the effect. In transport, neutralization means an exchange of original transport notes or transport documents with other transport notes or transport documents. In general, one is speaking about cancellation of the first transport note [2]. Neutralization of transport documents is in most cases associated with illegal logistics activities called „parallel trade ". Parallel trade is defined as a trade with products that takes place outside the official distribution [19]. Through the self-distribution of the system, companies can cause price differences across countries, taking advantage of national differences in consumer behavior. At the same time, merchants buy products in countries where they are being sold at lower prices and sell them in higher priced countries. There is no falsification of the product, but the product is imported from the country without the permission of the intellectual property owner [20].

Neutralization of transport note in "parallel trade" can be explained in Figure 2.

(1) The trader agrees with the seller (manufacturer) that he will distribute his product to a country where his product is not sold yet (e.g. Switzerland) if he provides a price lower than his original selling price. Lower sales price due to the entrance to new market. (2) The consignment note of the CMR is listed, showing the sender as manufacturer and the buyer is a company in Switzerland. (3) After the goods have been transported, the driver will be given a duty to neutralize, he will stop a vehicle for example at gas station and then he will neutralize the consignment note of the CMR (exchange it for another one). (4) Sender is a company in Switzerland and receiver will be a company in Germany. Trader will sell these goods in Germany for way higher price compared to price for which he bought the goods. (5) While the manufacturer has no idea that his goods are sold in Germany, where he already sells those goods [21]. The purpose of neutralizing the transport notes in "parallel trade" is to ensure a trade secret where the seller wants to prevent the recipient from knowing the manufacturer and its purchasing conditions [22]. Based on theoretical research, the following reasons for neutralizing consignment notes can be identified by:

- Reason A - when the seller does not want the manufacturer to find out to whom his product is sold In that case, driver loads the goods in the vehicle and writes out consignment note of the CMR including 


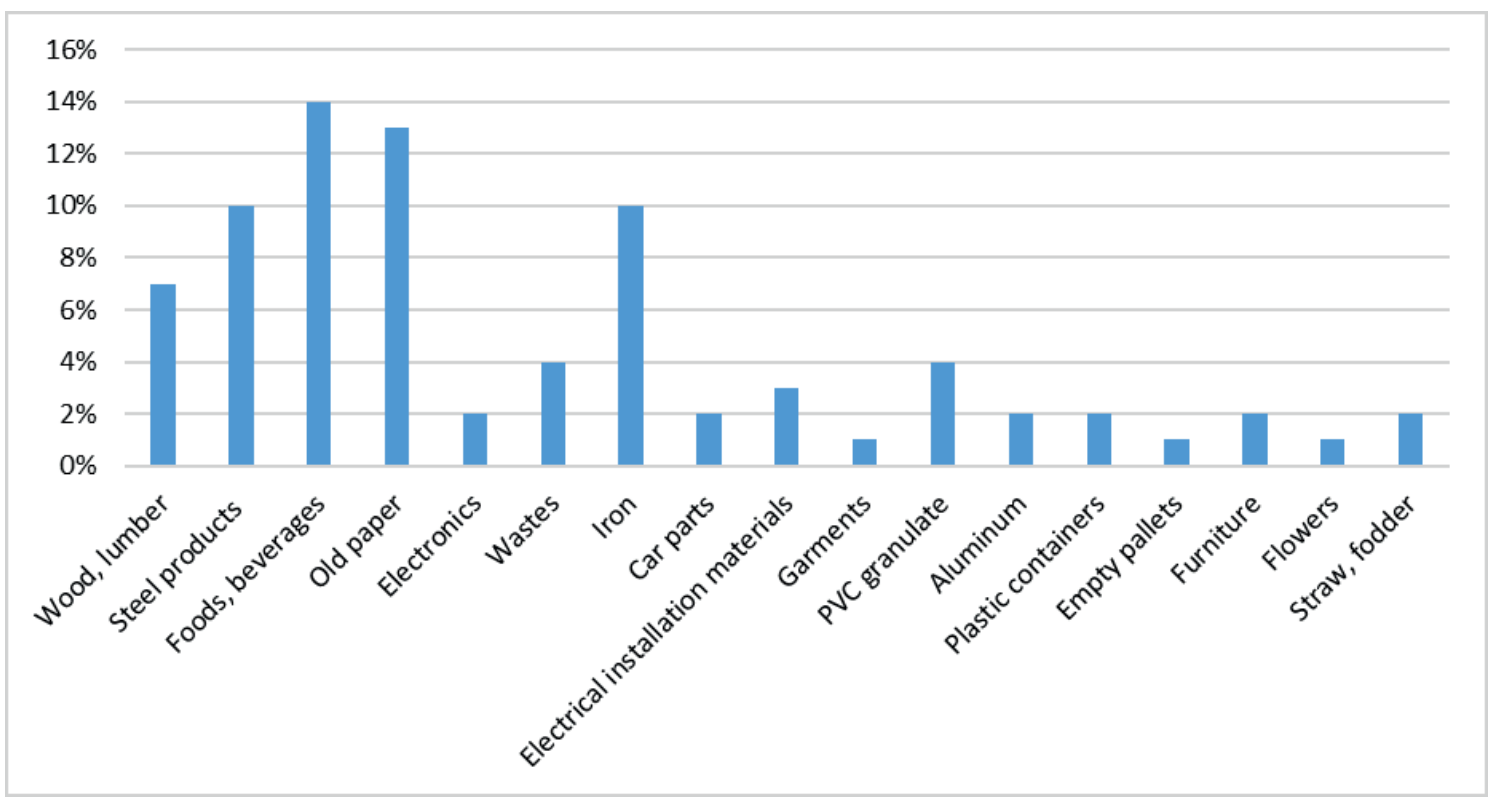

Figure 3 Carried goods at neutralization

the sender and the original receiver. After a while, the driver will be instructed to neutralize and he will write out new documents, which include a different receiver already.

- Reason B - when the seller does not want the customer to find out where the goods are produced

The driver loads the goods into the vehicle and the bill of loading is sent to the receiver's warehouse indicating the place of loading other than the actual one. In case of some random control on the road, driver will write out transport note in which the real final place of the load and unload is written correctly. However, the final customer will get documents including different place of loading compared to the real one, due to that he will never know who the real producer of goods is [23-24].

- Reason C - nobody does not know anything, means that producer has no idea where the final goods will be delivered and final customer has no idea from where the product came

This case occurs mainly when transported loads goods into a transport vehicle, write out the transport note which is stored in the warehouse of loading goods. Later, the transporter gets an order to neutralize and he will write out the new transport letter including the real sender of goods but a new receiver. Following this step, when he will get close to the new receiver, he will write out another document including the new sender and the new receiver who was already included in the second note. Based on this statement, one can easily say that in practice there are three ways of neutralizations of transport documents. Based on the theoretical identification of this issue with neutralizing transport documents, the research is conducted, which is described in next section. Thanks to that research, the objective was to confirm or refuse hypotheses, which were set at the beginning of this work.

\section{The conducted survey}

For acquiring information about neutralization of consignment note of CMR, a survey was conducted electronically, in a software called "Google Forms". After creation of a survey, the pre-test was done to confirm that questions are understandable enough. Later, this survey was sent to public on discussion forums, then it was resend through the social sites and added into groups including members of the road freight transport (transporters). There were 190 respondents who filled the survey. It consists of 3 questions. Objective of the first question was to know if asked transporters have any experience with neutralization of the CMR consignment note. The second question was aimed to obtain information about kinds of goods where the neutralization is used the most. The last question was meant to gather information about roads on which the neutralization is being done the most, as well as what is the country of loading goods and what is the country of unloading goods. The survey was realized with the main goal to get information from transporters and to know what is their experience with neutralization of documents and to find out what countries suffer from this issue the most. Majority of people who completed the survey were transporters who conduct transports through 18 countries, for example Germany, Spain, France...

Based on this survey the information was gathered that confirmed that transporters have real experience with neutralization of the CMR consignment note. It is known that $66 \%$ from asked respondents (transporters) have experience with neutralization and 34\% do not have experience with neutralization and they never heard about this term. Even due to the fact that none of professional books does not describe neutralization of the CMR consignment note, it is necessary to state that transporters are doing these practices on a regular basis. 


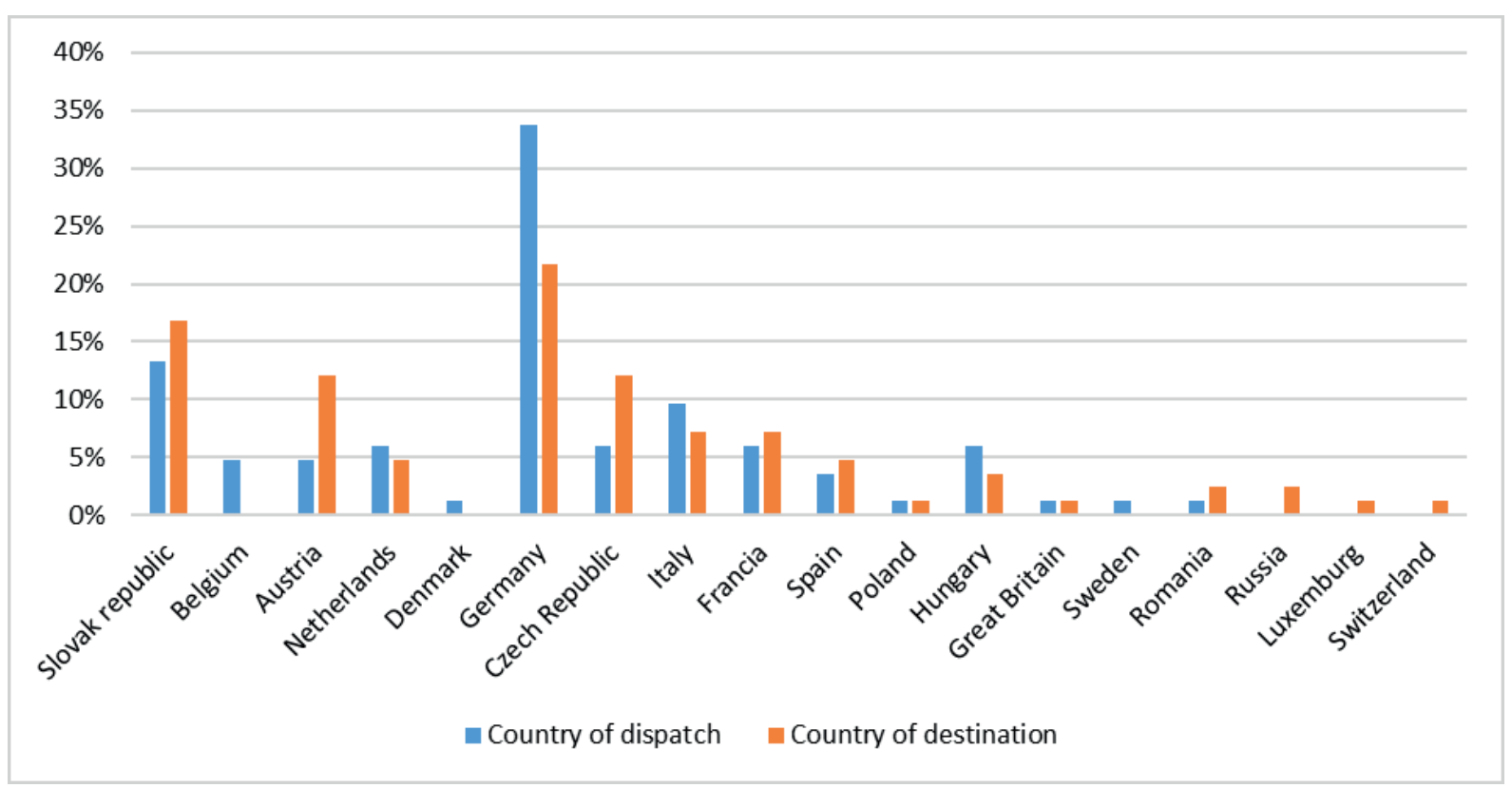

Figure 4 Country of dispatch and destination at neutralizing transport documents

The second part of this research was about question: For what kinds of goods the neutralization is the most requested? Results of this research are being shown in Figure 3. This picture describes certain categories of goods which transporters set as a "transported goods" which was written in the CMR consignment note in row number 9 (marking of goods). It is easy to see that neutralization is being done with different kinds of goods. Thus, neutralization is not linked to only one certain kind of goods. From this research one can see that neutralization is being done mostly during the transport of food and drinks, which represent $18 \%$ from overall transported materials and on the second place one can see old paper with $16 \%$. The third place is being represented by iron with $13 \%$. Less neutralized goods are textile materials and empty wooden pallets and flowers.

The last part of this research was focused on gathering information about roads of transport on which the neutralization was done the most. From carriers the information was sought on what kinds of roads they got the request to edit and neutralize the transport note. Considering the fact that multiple different roads were listed, they were at least divided into countries of sending and receiving goods. Results are shown in Figure 4, which shows that Germany is the country where neutralization is happening the most. Almost $35 \%$ answers are targeting Germany as a country of sending goods and in $22 \%$ of cases it is a country of receiving goods. Neutralization is also happening in Slovak Republic. Other countries listed on graph were not represented by the huge amount like Germany and Slovak Republic.

From this survey one can also say that neutralization is not being used just during the international transports but also during the transportations inside a country (cabotage) transports. $87 \%$ of carriers who entered this survey were ordered to neutralize the transport note during the international transport. Remaining 13\% were ordered during the internal transport.

\section{Conclusion}

The CMR, which sets the transport contracts during the international road freight transport is today the most important tool of dividing responsibility among carrier and customers of a transport. It also defines the trustworthy documents, which are necessary for realization of transport and which represent documents about realization of a transport, not only for parties but for the third party people as well. Considering the fact that there is not a trustworthy research about the fact that neutralization of transport notes happens in reality, main goal of this article was to apply the hypothesis that the neutralization is really happening around us. Research of authors confirmed that during the practical transport many carriers do neutralize the transport notes and documents. $66 \%$ of carriers who participated in the survey confirmed that on the request from side of the order of transport they had to realize the neutralization of transport notes. From the further research one can discuss that neutralization is not only linked to transport of certain goods but it affects many different categories and kinds of transported goods, as well. From this research follows that goods that being the most neutralized are food, drinks, paper, iron. The conclusion is also drawn that neutralization happens on different roads, while being the most frequent on roads between Germany and Slovakia. Neutralization is not used only during the international freight transport, but even during the internal transport, where many threats can occur while not following these requirements for sabotage. Neutralization of transport document is not a professional term and it is not defined in any law or order and not even in the CMR; one cannot say how the neutralization 
would affect sender, transporter and receiver. It will be suitable to focus on consequences of neutralization of the transport document. Considering the fact that it is a process of replacing original transport note by a new one, then the note loses its trustworthiness and it can make many different risks in practice, which can be a threat for all the named parties before or during the transport. It is also recommended to monitor the impact of using neutralization of the transport note, including the GDP or if there are not any scams done with the GDP. Next, it is recommended to research impact on insurance of responsibility of a carrier, claiming of goods, insurance of package and similar affairs linked to transport of goods.

\section{Acknowledgements}

The contribution was elaborated with the support of the Ministry of Education of the Slovak Republic VEGA No. 1/0566/18 KONECNY, V.: Research on the impact of supply and quality of transport services on the competitiveness and sustainability of demand for public transport.

This publication was realized with support of Operational Program Integrated Infrastructure 2014 2020 of the project: Innovative Solutions for Propulsion, Power and Safety Components of Transport Vehicles, code ITMS 313011V334, co-financed by the European Regional Development Fund.

\section{References}

[1] KAN, S. M., KURMANGALIYEVA, S. G., PLEKHANOV, P. A., TLEUOVA, Z. T., KALUGIN, O. A. Some aspects of methods elicitation economic expediency cargo carriage the different types of transport. Bulletin of The National Academy of Sciences of the Republic of Kazakhstan. 2015, 6(358), p. 66-70. ISSN 1991-3494, eISSN 2518-1467.

[2] POLIAK, M., POLIAKOVA, A. Relation of social legislation in road transport on driver's work quality. In: Tools of Transport Telematics TST 2015 : proceedings [online]. Vol. 531. Communications in Computer and Information Science. Cham: Springer, 2015. 978-3-319-24576-8, eISBN 978-3-319-24577-5, p. 300-310. Available from: https://doi.org/10.1007/978-3-319-24577-5_30

[3] DEFOSSEZ, D. CMR: what if the courts got it wrong? Uniform Law Review [online]. 2016, 21(1), p. 75-100. ISSN 1124-3694, eISSN 2050-9065. Available from: https://doi.org/10.1093/ulr/unw003

[4] LAMONT-BLACK, S. The UK supreme court on jurisdiction over successive CMR convention carriers and European Union rules. Uniform Law Review [online]. 2016, 21(4), p. 487-509. ISSN 1124-3694, eISSN 2050-9065. Available from: https://doi.org/10.1093/ulr/unw041

[5] SCHELIN, J. CMR convention in a law and economics perspective. Uniform Law Review [online]. 2016, 21(4), p. 434-440. ISSN 1124-3694, eISSN 2050-9065.Available from: https://doi.org/10.1093/ulr/unw036

[6] SPANJAART, M. The successive carrier: a relic from the past. Uniform Law Review [online]. 2016, 21(4), p. $522-532$. ISSN 1124-3694, eISSN 2050-9065.Available from: https://doi.org/10.1093/ulr/unw038

[7] Convention on the contract for the international carriage of goods by Road - United Nations [online]. Geneva, 1956. Available from: https://www.jus.uio.no/lm/un.cmr.road.carriage.contract.convention.1956/doc.html

[8] QUIGLEY, I. Freight carrier’s liability under the CMR convention 1956. Acta Oeconomica Pragensia [online]. 2006, 14(4), p. 41-45. ISSN 0572-3043, eISSN 1804-2112. Available from: https://doi.org/10.18267/j.aop.99

[9] VERHEYEN, W. National judges as gatekeepers to the CMR convention. Uniform Law Review [online]. 2016, 21(4), p. 441-456. ISSN 1124-3694, eISSN 2050-9065. Available from: https://doi.org/10.1093/ulr/unw039

[10] RADIONOV, N. Limitation of liability right in road freight carriage in Croatia: an extinct institute. Uniform Law Review [online]. 2016, 21(4), p. 457-468. ISSN 1124-3694, eISSN 2050-9065. Available from: https://doi.org/10.1093/ulr/unw035

[11] UN Transport Agreements and Conventions [online]. Available from: https://www.unece.org/trans/maps/un-transportagreements-and-conventions-25.html

[12] FERRER, J. C. The CMRconvention - a pillar of international carriage of goods by road. Uniform Law Review [online]. 2006, 11(3), p. 517-521. ISSN 1124-3694, eISSN 2050-9065. Available from: https://doi.org/10.1093/ulr/11.3.517

[13] BONNET, J. C. CMR - international convention of Geneva relating to the contract for the international carriage of goods by road 19 May 1956. Uniform Law Review [online]. 2016, 21(4) p. 418-420. ISSN 1124-3694, eISSN 2050-9065. Available from: https://doi.org/10.1093/ulr/unw052

[14] SZYMONIK, A. International logistics. Lodz: University of Technology, 2014. ISBN 978-83-7283-611-3.

[15] VUKOVIC, A. Units of account in international and domestic transport law. Nase More [online]. 2013, 60(1-2), p. 11-16. ISSN 0469-6255, eISSN1848-6320. Available from: https://hrcak.srce.hr/104450

[16] DENES, A. Considerations on the contract for the international carriage of goods by road. Revista de la Facultad de Derecho [online]. 2018, 44, p. 253-285. ISSN 0797-8316, eISSN 2301-0665. Available from: https://doi.org/10.22187/ rfd2018n44a9

[17] LORENC, A., KUZNAR, M. An intelligent system to predict risk and costs of cargo thefts in road transport. International Journal of Engineering and Technology Innovation [online]. 2018, 8(4), p. 284-293. ISSN 2223-5329, eISSN 2226-809X. Available from: http://ojs.imeti.org/index.php/IJETI/article/view/1013 
[18] SKER, T. Analysis of road carriers liability for robbery of cargo according to CMR convention. Promet - Traffic and Transportation [online]. 2003, 15(6), p. 371-374. ISSN 0353-5320, eISSN 1848-4069. Available from: https://traffic.fpz. hr/index.php/PROMTT/article/view/903

[19] ONSTEIN, A. T. C., TAVASSZY, L. A., VAN DAMME, D. A. Factors determining distribution structure decisions in logistics: a literature review and research agenda. Transport Reviews [online]. 2019, 39(2), p. 243-260. ISSN 0144-1647, eISSN 1464-5327. Available from: https://doi.org/10.1080/01441647.2018.1459929

[20] STOTHERS, CH. Parallel trade in Europe: intellectual property, competition and regulatory law. British Library Cataloguing in Publication Data. 2007. ISBN 978-1-84113-437.

[21] MUKHERJEE, A., ZHAO, L. Profitable parallel trade in unionized. Journal of Economics [online]. 2012, 107(3), p. 267-276. ISSN 0931-8658, eISSN 1617-7134. Available from: https://doi.org/10.1007/s00712-012-0267-7

[22] ARRUNADA, B., GONZALEZ-DIAZ, M., FERNANDEZ A. Determinants of organizational form: transaction costs and institutions in the European trucking industry. In: Conference held in honor of Oliver E. Williamsons 70th Birthday: proceedings. 2002, p. 867-882.

[23] LEWANDOWSKI, P. Attempts to protect the internal market for road transport in specific European Union countries. Scientific Journals of the Maritime University of Szczecin / Zeszyty Naukowe Akademii Morskiej w Szczecinie [online]. 2016, 47, p.141-146. ISSN 1733-8670, eISSN 2392-0378. Available from: https://doi.org/10.17402/161

[24] STERNBERG, H., HOFMANN, E. Impact of the European road transport market deregulation: the case of cabotage in Germany. International Journal of Business and Systems Research. 2017, 11(4), p. 417-428. ISSN 1751-200X, eISSN 1751-2018. 